Int. J. Dev. Biol. 62: 623-629 (2018)

https://doi.org/10.1387/ijdb.180109kx

\title{
Prolactin stimulation affects the stem cell-dependent mammary repopulating ability of embryonic mammary anlagen
}

\author{
JIAZHE SONG ${ }^{1,2}$, FANGRONG DING ${ }^{3}$, SONG LI ${ }^{3}$, SIYING PENG ${ }^{1}$, YIXIANG ZHU ${ }^{1}$ and KAI XUE*,1 \\ ${ }^{1}$ College of Basic Medical Sciences, Dalian Medical University, Dalian, \\ ${ }^{2}$ State Key Laboratories for AgroBiotechnology, College of Biological Sciences, China Agricultural University, Beijing \\ and ${ }^{3}$ National Animal Genetic Research Center, Beijing, P. R. China
}

\begin{abstract}
The function of prolactin in mammary gland development and lactation has been demonstrated in previous studies. However, the potential action of prolactin on mammary duct morphogenesis at mammary anlagen stage (E13.5 15.5) has not been elucidated. Transplantation of mammary cells or tissue is an effective approach for the regeneration of damaged mammary gland. Defining the actions of prolactin stimulation on embryonic mammary anlagen has important implications for defining the role of prolactin in the poorly understood processes of mammary duct morphogenesis and regeneration. Here, we have employed the GFP-transgenic mouse model to examine the effects of prolactin on stem cell activity. Using in vitro prolactin stimulation and transplantation of E14.5 mouse mammary anlagen, we identified the influence of prolactin on their mammary repopulating ability. Furthermore, using immunofluorescence staining and microarray analysis, the influence of prolactin on cell characteristics and gene expression in mammary anlagen were also profiled. We also demonstrate that E14.5 mouse mammary anlagen possess mammary stem cells (MaSCs) which achieve mammary repopulation. Furthermore, we found that in vitro prolactin stimulation elevates MaSC activity and promotes the mammary repopulating ability of mammary anlagen. Finally, microarray and pathway analysis showed that MAPK, Akt and JAK-STAT signaling was activated by prolactin stimulation, and drove the mammary repopulation of mammary anlagen. We conclude that prolactin stimulation elevates the stem cell-dependent mammary repopulating ability of embryonic mammary anlagen.
\end{abstract}

KEY WORDS: prolactin, mammary anlagen, mammary stem cell, mammary duct morphogenesis, mammary repopulation

\section{Introduction}

The transplantation of mammary cell or tissue is an effective approach for the regeneration of functional mammary gland. Mammary anlagen stage (E13.5 15.5) is a transition period, which mammary rudiment begins with the formation of lens-like placodes followed by the appearance of bulb-shaped buds (Robinson et al., 1999). And it is also a key stage for sex-specific mammary duct morphogenesis, which is fundamental to the regeneration of mammary gland (Robinson et al., 1999; Robinson 2007). Given that mammary stem cells (MaSCs) possess the ability to generate all differentiated cell types in the mammary gland, it is conceivable that MaSCs in mammary anlagen may be the main power to drive the mammary repopulation (Shackleton et al., 2006; Stingl et al.,
2006; Van Keymeulen et al., 2011; Jiazhe Song 2014). Therefore, the stimulations for increasing stem cell activities will promote the growth of embryonic mammary anlagen, and elevate the efficiency of mammary repopulation.

Different hormonal signals elicited by the hypothalamic-ovarian-pituitary axis, such as estrogen, growth hormone and prolactin (PRL) (Daniel et al., 1987; Silberstein et al., 1994; Walden et al., 1998; Oakes et al., 2008), are shown to modulate mammary development and lactation. For mammary development, most studies of PRL functions have concentrated on its role in alveolar development during pregnancy and lactogenesis (Oakes et al.,

Abbreviations used in this paper: MaSC, mammary stem cell; MFP, mammary fat pad; PRL, prolactin.

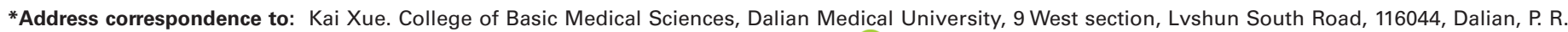
China. Tel.: +86-411-86118660. Fax: +86-411-86110378. Email: nkx123xuekai@ sina.com - (iD https://orcid.org/0000-0002-8068-1138
} 
2008). However, few previous studies also reported that PRL could promote the proliferation of mammary epithelial cells and play an essential role in mammary ductal side branching (Horseman et al., 1997; Oakes et al., 2008; Leehy et al., 2018). In addition, estrogen is a well known ovarian hormone that is critical to embryonic mammary ductal morphogenesis (Silberstein et al., 1994; Walden et al., 1998; Leehy et al., 2018), and PRL and nuclear PRL receptor (PRLR) can enhance the expression of the estrogen receptor (ER) and progesterone receptor (PR) (Gutzman et al., 2004; Fiorillo et al., 2013). Notably, PRL can also drive ER-dependent ductal expansion by prolonging Akt and ERK activities (Arendt and Schuler 2008). These findings implying that $P R L$ and its downstream signal pathway may be also important to the development of embryonic mammary anlagen. Recently, Linda A. Schuler and her team reported that PRL could alter the mammary epithelial hierarchy and increase mammary stem/progenitor activity (O'Leary et al., 2017), suggesting that PRL may influence early embryonic mammary development by promoting epithelial cell proliferation and increasing stem cell activity. However, this potential PRL action on embryonic mammary tissue has not been well clarified until now.

To investigate the actions of PRL in mammary anlagen development and mammary repopulation, we employed the GFP-transgenic mouse model to examine the effects of PRL on stem cell activity, which can drive mammary duct morphogenesis. By the in vitro $\mathrm{PRL}$ stimulation and the transplantation of E14.5 mouse mammary anlagen, we identified the influence of PRL on the mammary repopulating ability of mammary anlagen. Furthermore, using immunofluorescence staining and microarray analysis, the influence of PRL on cell characteristics and gene expressions in mammary anlagen were also profiled. Collectively, defining the actions of PRL stimulation on early embryonic mammary anlagen has important implications for defining the role of PRL in the poorly understood mammary duct morphogenesis and regeneration.

\section{Results}

Co-expression of CD24 and CD29 in fetal mouse mammary anlagen implies the possibility for mammary repopulation by transplanting mammary anlagen cells

The male and female mouse mammary anlagen show different configurations at mammary anlagen stage (E13.5-15.5) (Song et al., 2015). To collect female mouse mammary anlagen, mice in estrus were mated and the age of the embryo was determined by checking vaginal plugs. Due to this method for timing pregnant embryos is not exactly precise, we selected E14.5 mice, which possess typical properties of mammary anlagen stage (E13.515.5). First, we dissected mammary anlagen from E14.5 mice to examine their structures. Compared to the small black entity structure of male mouse mammary anlagen, E14.5 female mouse mammary anlagen showed a knob-like structure, which contained a translucent cavity (Fig. 1A) (Robinson et al., 1999; Veltmaat et al., 2003; Han et al., 2006). Then the DAPI-staining indicated that E14.5 mammary anlagen show a simple convex lens-like structure, and comprise mammary bud epithelium in its central area (Fig. 1B). We also examined the epithelia markers in E14.5 mouse mammary anlagen, and showed that the expressions of $\mathrm{K} 8$ and $\mathrm{K} 14$ at E14.5 were mainly concentrated on the central region of mammary anlagen, suggesting that the mammary epithelial cells locate in mammary anlagen bud (Fig. 1C). As the markers for sorting adult

mammary stem cells (MaSCs), CD24, CD29 and CD49f have been applied to analyze fetal MaSCs (Shackleton et al., 2006; Stingl et al., 2006; Van Keymeulen et al., 2011; Spike et al., 2012; Jiazhe Song 2014). To identify the mammary repopulating ability of early embryonic mammary anlagen, the potential stem cell activities were detected using antibodies against the cell surface markers of CD24 and CD29, recombined with the anti-cytokeratin antibody, which were identified as capable of drawing the profile of mammary anlagen (Han et al., 2006). As shown in Fig. 1D, the mammary anlagen extensively expressed CD24 and CD29. Concretely, the expression of CD29 was especially intensive inside the mammary anlagen, but weak in the surrounding stromal cells; Correspondingly, CD24 had an extensive expression in both mammary anlagen and its surrounding stromal cells (Fig. 1D). These expression patterns

A

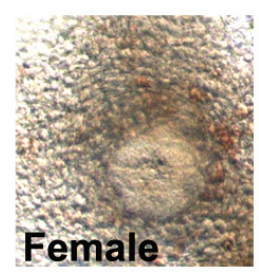

C
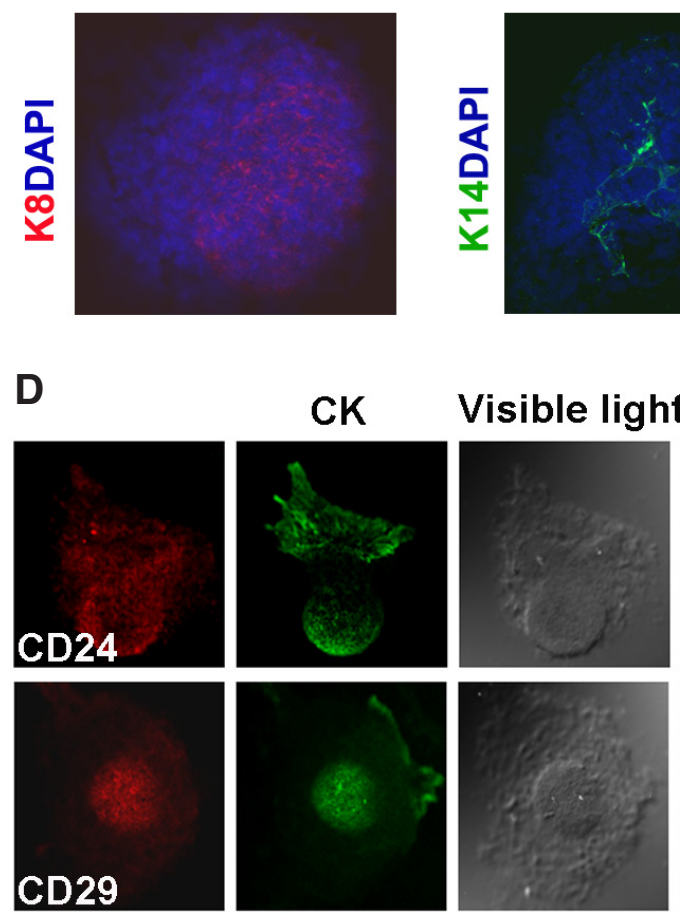

Fig. 1 The identification of E14.5 mouse mammary anlagen. (A) Dis sected mammary anlagen from E14.5 male and female mice. Scale bar, $1000 \mu \mathrm{m}$. (B) E14.5 mouse mammary anlagen stained with DAPl; the amount of mammary mesenchyme (MM) left associated with the mammary bud epithelium (MBE) upon microdissection are indicated. Scale bar, 100 $\mu \mathrm{m}$. (C) The expression of keratin 8 (K8, red), and keratin 14 (K14, green) in E14.5 mammary anlagen were defined by immunostaining. The DNA of mammary anlagen were stained with DAPI (blue). (D) Expression of CD24 and CD29 in mammary anlagen. The expression of CD24,CD29 (red) and cytokeratin (CK, green) were defined by immunostaining. Scale bar, $100 \mu \mathrm{m}$. 
of CD24 and CD29 revealed that fetal mouse mammary anlagen might possess high stem cell activities. Importantly, these data showed a possibility for the mammary repopulation by transplanting mammary anlagen.

\section{In vitro culture and prolactin stimulation of E14.5 mouse mammary anlagen}

To investigate the influence of PRL on mammary anlagen cells, we tried to culture the $\mathrm{E} 14.5$ mouse mammary anlagen in vitro. After 24 hours, we found that the surrounding cells of mammary anlagen adherent proliferated and enlarged the distribution range in culture plate (Fig. 2A and Suppl. Fig. S2). Furthermore, the 72 hourscultured mammary anlagen showed a distributed and separable construction (Fig. 2A). And based on the staining of cytokeratins, the 72 hours-cultured mammary anlagen comprise more epithelial cells, compared with uncultured mammary anlagen (Fig. 1C and 2B). Then the K14-staining of 10 days-cultured mammary anlagen showed that the epithelial cells covered the culture plate (Suppl. Fig. S2). These results confirmed that mammary anlagen epithelial cells keep proliferating during in vitro culture. Moreover, we further identified the characteristic of 72 hours-cultured mammary anlagen cells by performing immunofluorescence assays. The results showed that cytokeratin 14 (K14) expressed in the majority of cells (Fig. $2 B$ ), suggesting that most of 72 hours-cultured mammary anlagen cells were undifferentiated epithelial cells (Van Keymeulen et al., 2011; Spike et al., 2012). And the co-expressions of K14 and K18 in few cells indicated that minority of 72 hours-cultured mammary anlagen cells had underwent differentiations (Fig. 2B). Furthermore, we also detected the expressions of CD24 and CD 49f, which were ever applied to purify MaSCs (Spike et al., 2012), and found that they extensively expressed in 72 hours-cultured mammary anlagen cells (Fig. 2B). Compared with uncultured mammary anlagen, no obvious difference of CD24 expression was found in 72 hours-cultured mammary anlagen (Fig. $1 \mathrm{C}$ and 2B). These results demonstrate that the in vitro culture only produces limited impact on the characteristic and stem cell activities of E14.5 mammary anlagen. On the basis of in vitro culture, the PRL stimulation was added to the E14.5 mammary anlagen for 24 hours. The following immunofluorescence and flow cytometry analysis showed that PRL stimulation obviously enhanced the expressions of CD24 and CD29 in mammary anlagen cells (Fig. 2 C,D,E). Considering the

Fig. 2 In vitro culture and prolactin stimulation of E14.5 mouse mammary anlagen. (A) The in vitro culture of $E 14.5$ mouse mammary anlagen. The constructions of $\mathrm{O}$ (left), $24 \mathrm{~h}$ (middle) and $72 \mathrm{~h}$ (right) -cultured mammary anlagen are shown, respectively. Scale bar, 1000 mm. (B) Expression of different cell surface markers in mammary anlagen. The expressions of keratin14 (K14, green), keratin18 (K18, red), CD49f (red) and CD24 (red) in E14.5 mammary anlagen were defined by immunostaining. The DNA of mammary anlagen were stained with DAPI (blue). Scale bar, $100 \mu \mathrm{m}$. (C) Expression of CD24 and CD29 in mammary anlagen cells. E14.5 mammary anlagen were cultured in normal D/F12 medium with FBS for $24 \mathrm{~h}$. Then the digested mammary anlagen cells were analyzed by flow cytometry assay. (D) Expression of CD24 and CD29 in prolactin (PRL)-stimulated mammary anlagen cells. E14.5 mammary anlagen were stimulated with $P R L$ for $24 \mathrm{~h}$ $(F B S+P R L)$. Then the digested mammary anlagen cells were analyzed by flow cytometry assay. (E) Expression of CD24 and CD29 in PRL-stimulated mammary anlagen. E14.5 mammary anlagen were stimulated with PRL for $24 \mathrm{~h}$. Then the expression of CD24 and CD29 (red) were defined by immunostaining. Scale bar, $100 \mu \mathrm{m}$. function of CD24 and CD29 in MaSCs identification, these results implied that the in vitro PRL stimulation may elevate potential stem cell activities of fetal mouse mammary anlagen.

\section{Prolactin stimulation promotes the mammary repopulating efficiency of mammary anlagen}

To analyze the mammary repopulating abilities of E14.5 mouse mammary anlagen, the mammary anlagen from GFP-ICR mice were transplanted into cleared mammary fat pads (MFPs) of

A
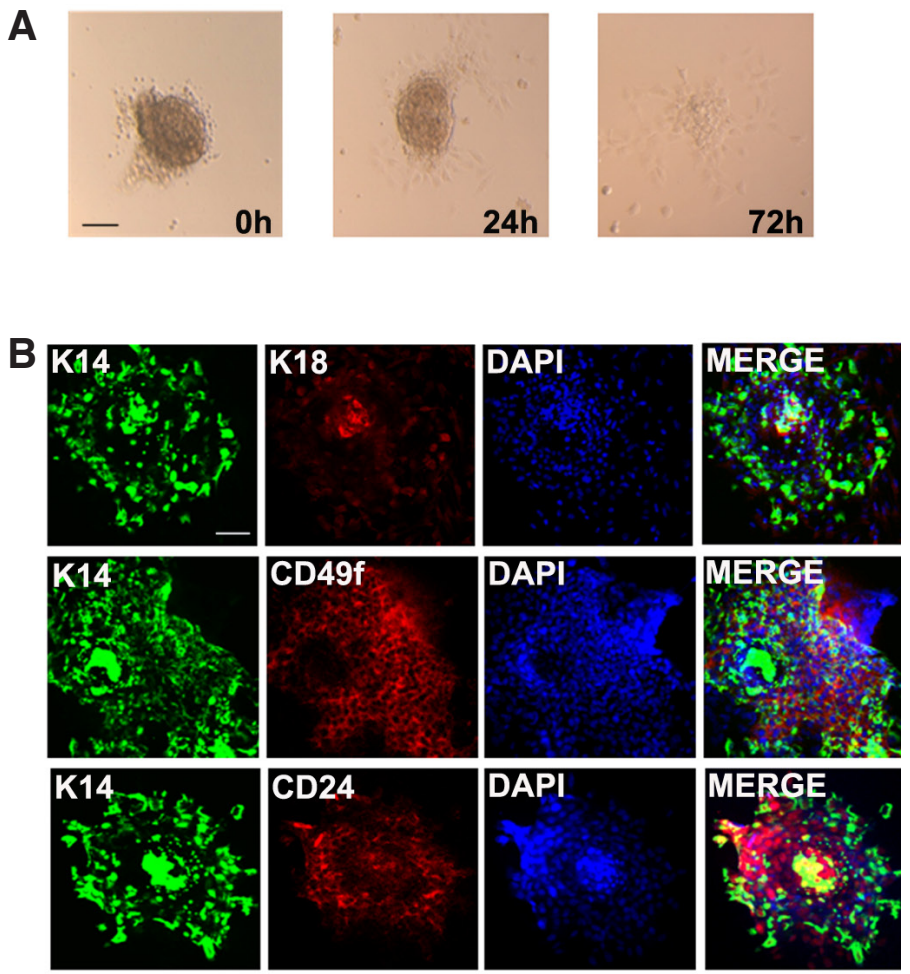

C

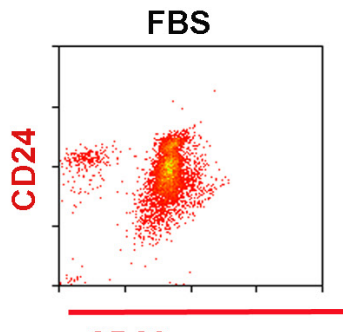

D

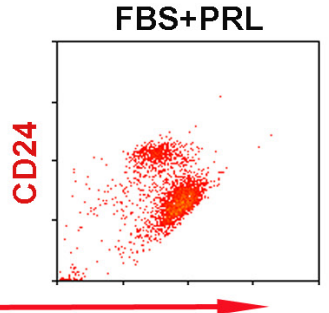

CD29
E

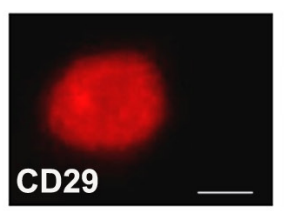

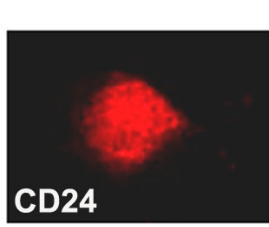
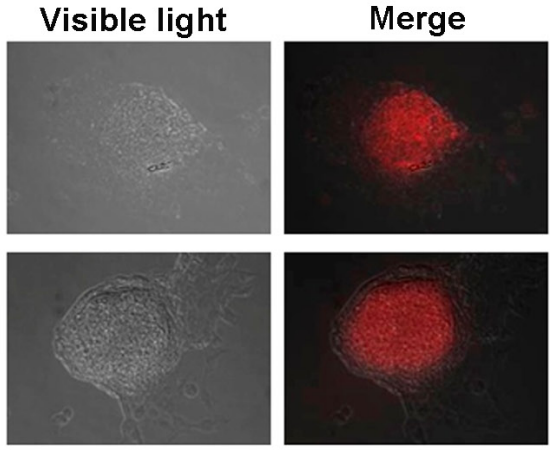
recipient Scid mice. And to further identify the influence of $P R L$ on mammary anlagen, the E14.5 mammary anlagen were treated with PRL for 24 hours before transplantation, and compared to the control samples (cultured in normal FBS medium with no PRL stimulation). After 8 weeks, we dissected the recipients, and found that both PRL-stimulated mammary anlagen and control samples could regenerate mammary ductal outgrowth (Fig. 3A, green color). However, in contrast to the transplantation of control samples, transplantations of PRL-stimulated mammary anlagen regenerated thicker mammary gland duct, which resemble as the mammary tissue in pregnancy cycle (Fig. 3A, green color). Next, the mammary repopulation by transplanting different numbers of mammary anlagen were statistical analyzed, and list in Table 1 and Table 2. The statistic analysis showed that PRL stimulation obviously promoted the mammary repopulating efficiency of mammary anlagen. Combined with the above results (Fig. 2 C,D,E), we can conclude that in vitro PRL stimulation elevates the MaSC activities and promotes the mammary repopulating ability of embryonic mammary anlagen.

\section{In vitro prolactin stimulation activates mammary repopulating- associated gene expression}

Given that the in vitro PRL stimulation promotes the mammary repopulating ability of E14.5 mammary anlagen, we further verified the potential mechanisms by analyzing gene expressions. After the in vitro culture for 24 hours, the global gene expressions of PRL-stimulated mammary anlagen and control samples were profiled (extracted RNAs from each sample and hybridized with Affymetrix Mouse MOE430 Genome Arrays). Approximately 45101 probe sets representing 21685 transcripts were detected in each

TABLE 1

\section{THE ENGRAFTMENT RATES OF CLEARED MAMMARY FAT PADS DERIVED FROM TRANSPLANTING E14.5 MAMMARY ANLAGEN}

\begin{tabular}{cc}
$\begin{array}{c}\text { Number of transplanted } \\
\text { anlagen per MPF }\end{array}$ & $\begin{array}{c}\text { Number of outgrowths/ } \\
\text { number of injected fat pads }\end{array}$ \\
\hline 1 & $1 / 4$ \\
2 & $1 / 5$ \\
3 & $3 / 4$ \\
4 & $4 / 5$ \\
5 & $5 / 5$
\end{tabular}

E14.5 mouse mammary anlagen were separated with surrounding cells and cultured in normal D/ F12 medium for 24 hours. Then they were injected as indicated number into cleared mammary fat pad (MFP). The recipient MFPs were examined at the 8th week after transplantation.

TABLE 2

\section{THE ENGRAFTMENT RATES OF CLEARED MAMMARY FAT PADS DERIVED FROM TRANSPLANTING PRL-STIMULATED MAMMARY ANLAGEN}

\begin{tabular}{cc}
$\begin{array}{c}\text { Number of transplanted } \\
\text { anlagen per MPF }\end{array}$ & $\begin{array}{c}\text { Number of outgrowths/ } \\
\text { number of injected fat pads }\end{array}$ \\
\hline 1 & $2 / 3$ \\
2 & $3 / 3$ \\
3 & $4 / 4$ \\
4 & $4 / 4$ \\
5 & $5 / 5$ \\
\hline
\end{tabular}

E14.5 mouse mammary anlagen were separated with surrounding cells and treated with prolactin (PRL) for 24 hours. Then they were injected of indicated number into cleared mammary fat pad (MFP). The recipient MFPs were examined at the 8th week after transplantation. sample, of which 2159 transcripts were differentially expressed ( $>$ or $=2$-fold) between the two groups, corresponding to 938 upregulated and 1221 down-regulated transcripts in PRL-stimulated mammary anlagen compared to control samples (Suppl. Fig. S1A). Moreover, based on the pathway analysis (Suppl. Fig. S1B) and the relative reports (Bridgewater et al., 2017; O'Leary et al., 2017; Leehy et al., 2018), we selected several mammary repopulatingassociated genes, which were activated by $\mathrm{PRL}$ stimulation. As shown in Fig. 3B, all these mammary repopulating-associated genes were up-regulated in PRL-stimulated mammary anlagen. And the gene profiling analysis also confirmed that the downstream gene expressions (such as Stats, c-Myc and Bcl-2) exhibited cascade amplification effect. The prolactin-mediated downstream pathways in mammary development have been reported by many previous studies (Damiano and Wasserman 2013; Fiorillo etal., 2013; Bridgewater et al., 2017; O'Leary et al., 2017). According to the previous reports and our verification, the MAPK, Akt and JAK-STAT signaling can be activated by PRL stimulation, and further initiate different downstream gene expressions, which finally increase stem cell activities and drive the mammary repopulating process (Fig. $3 \mathrm{C}$ ).

\section{Discussion}

The multipotential cells are critical for the morphogenesis and maintenance of mammary gland at different development stage (Van Keymeulen et al., 2011). Mammary anlagen stage is the beginning of mammary rudiment, which achieves the formation of lens-like placodes followed by the appearance of bulb-shaped buds (Robinson et al., 1999). Although the studies aimed at mammary gland regeneration have proved that mammary anlagen are capable of repopulating whole mammary ductal tree (Robinson et al., 2001; Gallego et al., 2002), little is known about fetal MaSCs in mammary anlagen. In previous study, the potential distribution of fetal MaSCs in mouse mammary anlagen were identified and found that mammary anlagen only resided with rare stem cells (Spike et al., 2012; Jiazhe Song 2014). Therefore, the increase of stem cell activities at mammary anlagen stage plays a key role in the improvement of mammary repopulating efficiency. In our present study, PRL were applied to stimulate E14.5 mouse mammary anlagen in vitro, and produced a remarkable promotion of stem cell activities, which is essential for mammary repopulation (Fig. 2 C,D,E; Table 1 and 2). These results resemble previous studies, implying that PRL could alter the mammary repopulating ability of mammary anlagen by increasing stem cell activities (O'Leary et al., 2017). Given the importance of mammary stem cells (MaSCs) in the cell proliferation, growth and regeneration of mammary gland, the stem cell activities in mammary tissues at different developmental stages is one of the important preconditions for mammary regeneration. On the basis of this present study, the PRL stimulation elevates the stem cell-dependent mammary repopulating ability of embryonic mammary anlagen. Since the transplantation of mammary cell or tissue is an effective approach for the repair of mammary gland construction and regeneration of functional mammary gland, the application of PRL stimulation in the clinical therapy of mammary gland regeneration may be serving as a potential procedure for the advanced treatment of transplantation.

Although the function of PRLin MaSC-drived mammary development have been proved in previous studies (Oakes et al., 2008), the mechanism of PRL-associated elevation of stem cell activities 
remains unclear. Current knowledge regarding the increase of intraembryonic adult stem cells is fundamental for understanding organogenesis. As reported previously, the MaSCs are rare in early embryonic mammary anlagen and increase rapidly until E18.5 (Spike et al., 2012; Jiazhe Song 2014), indicating that the number of MaSC is a key factor for the mammary duct morphogenesis. According to the pathway analysis, the PRL-mediate elevation of stem cell activities was mainly depending on PRLR and its downstream signaling (Fig. 3C and Suppl. Fig. S1). Concretely, STAT proteins (STAT1, STAT3, and STAT5), the downstream effectors of

A
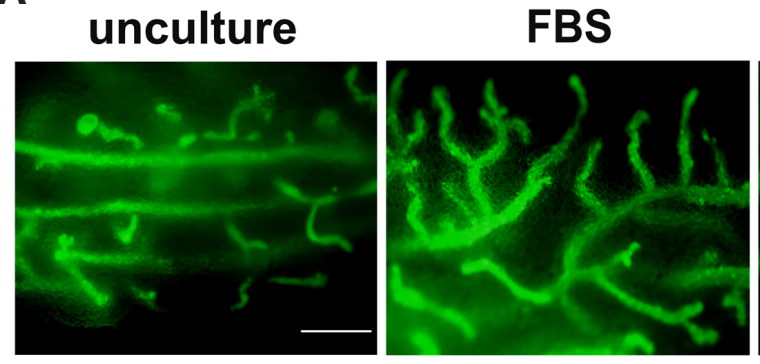

B

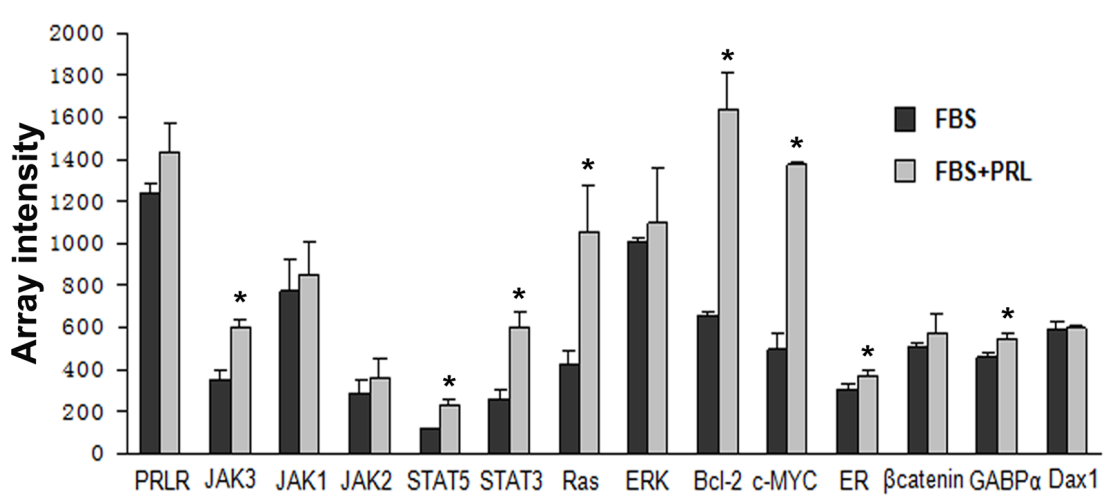

C

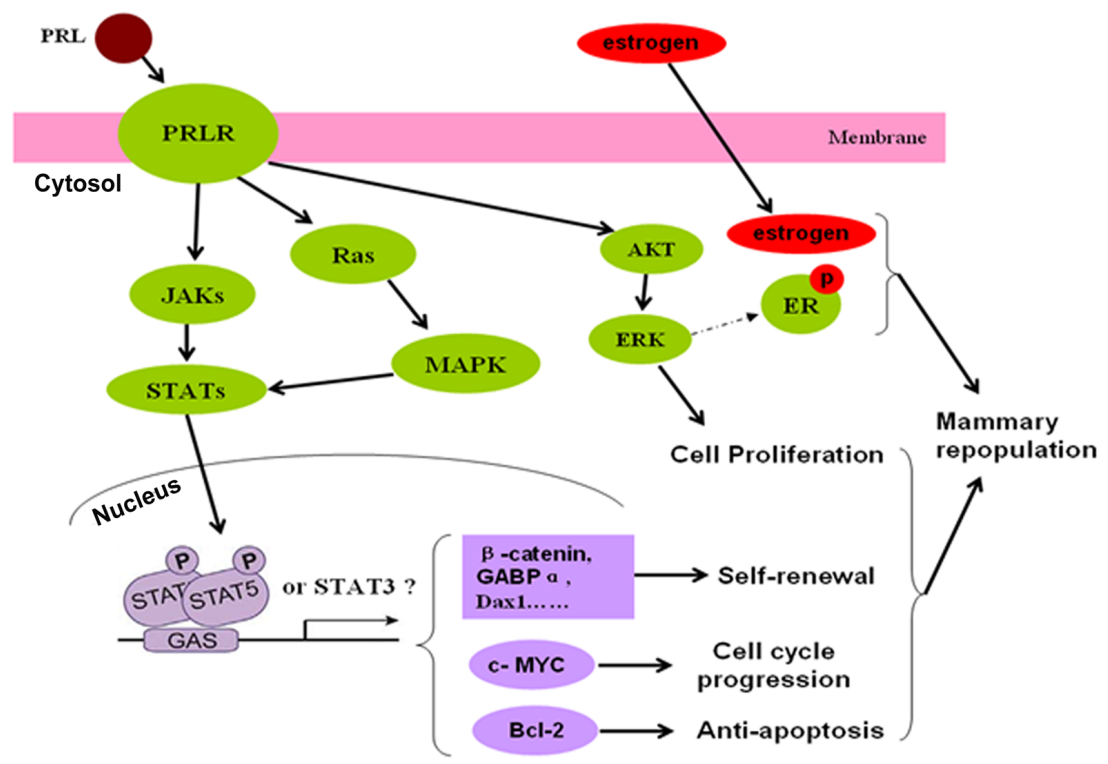

PRLR, are involved in all stages of mammary gland development (Damiano and Wasserman 2013; Haricharan and Li 2014; Leehy et al., 2018). Our results about the difference in gene expression profile between PRL-stimulated mammary anlagen and control sample also showed that PRLR may lead to the activations of the canonical Jak2/STAT5 or Jak1/STAT3 pathways in PRL-stimulated mammary anlagen, followed by the up-regulation of downstream genes (Bcl-2, c-MYC, $\beta$-catenin, GABP $\alpha$ and Dax1) (Fig. 3 B,C). Furthermore, based on the microarray data and pathway analysis, MAPK signal transduction, which is another pathway to activate STAT proteins, were also present in PRL-stimulated mammary anlagen (Fig. 3 and Suppl. Fig. S1). These findings indicated that the PRLR-mediated JAK-STAT signaling was a main pathway to promote the proliferation and self-renew of MaSCs in PRL-stimulated mammary anlagen (Fig. 3). In addition, previous studies reported that $P R L$ acts in synergy with the steroid hormones estrogen and progesterone to promote mammary growth, development, and differentiation (Horseman 1999; Fiorillo et al., 2013). Our study also found that the PRL stimulation of mammary anlagen induced the up-regulation of ER expression (Fig. 3B). These findings suggested an extensive paracrine crosstalk occurs between ER and PRL signaling, creating a continuum of overlapping and highly integrated signaling pathways (Fig. 3C). Therefore, the PRL stimulation activates different signal transductions, and further induces the elevation of stem cell activities, which promote the mammary repopulating efficiency of mammary anlagen (Table 1 and 2).

During embryonic mammary development, fetal MaSCs undergo proliferation, migration and invasion, which do not occur in the resting adult mammary gland, and resemble as the progression of breast cancer (Veltmaat et al., 2003). Here the $P R L$-induced functional changes and altered transcript levels for key regulators indicated that $P R L$ can strongly influence the breast cancer-associated signal transductions (Fig. 3), such as JAK1-STAT3 and ER signaling (Fiorillo et al., 2013; Haricharan

Fig. 3. Comparative analysis of prolactin-stimulated mouse mammary anlagen and control samples. (A) The morphology of 8 week-regenerated duct outgrowths from different mammary anlagen. E14.5 mammaryanlagen from GFP-ICR mice were treated with prolactin (PRL) stimulation for 24 hours (FBS+PRL), and compared to the control samples (FBS). Then the different mammary anlagen were transplanted into cleared mammary fat pads (MFPs) of recipient Scid mice. After 8 weeks, the recipients were dissected, showing different morphology. Arrow indicates the mammary duct enlarged with abnormal route. Scale bar, 500 um. (B) Array intensity of $m R N A$ profiles of PRL-stimulated (FBS+PRL) mouse mammary anlagen and control samples (FBS). The data for each cell population were obtained from three independent experiments. The $P$ values were produced by the comparison between PRL-stimulated mammary anlagen and control samples. ${ }^{*}$ means $P<0.05$. (C) The model of PRL-stimulated cell signaling in mammary anlagen. 
and Li 2014; Bridgewater et al., 2017; O’Leary et al., 2017; Leehy et al., 2018). In particularly, the transplantations of PRL-stimulated mammary anlagen regenerated anomalous thick mammary gland duct (Fig. 3A, green color), representing the over-proliferation of mammary epithelial cells. As reported previously, PRL regulates the activity of ovarian hormones by modulating the expressions of well-characterized transcriptional factors to augment stem/progenitor populations and perturb differentiation pathways, which may contribute to the development of breast cancer (O'Leary et al., 2017). Our results found that PRL stimulation elevated the stem cell activities of E14.5 mammary anlagen but also activated ER expression (Fig. 3), regulating downstream pathways, which are known to contribute to breast cancer biology. However, the 30-weeks $\mathrm{GFP}^{+}$duct enlarged with abnormal route outgrowth regenerated in cleared mammary fat pad using PRL-stimulated mammary anlagen suggested that the in vitro PRL stimulation induced the hyperplasia of mouse mammary gland but still not produced breast cancer (data not shown). Although the importance of PRL in breast cancer development and risk is less well-defined as compared to ovarian steroids (Rose-Hellekant et al., 2003; Tworoger et al., 2013; Leehy et al., 2018), more researches in this aspect should be done in the future work.

In conclusion, our findings demonstrate that E14.5 mouse mammary anlagen possess fetal MaSCs and the capability to achieve mammary repopulation. The in vitro culture is an ideal model for exploring the effect of stimulations to mammary anlagen. On this basis, we found that in vitro PRL stimulation elevates the MaSC activities and promotes the mammary repopulating ability of embryonic mammary anlagen. Then, by the microarray analysis, the MAPK, Akt and JAK-STAT signaling were found activated by PRL stimulation, and further drive the mammary repopulation of mammary anlagen. However, our findings also illuminate the role of PRL and crosstalk with ovarian steroids in the regulation of the MaSC activaties and raise new hypotheses concerning its role in the risk for breast cancer.

\section{Materials and Methods}

\section{Mice}

We declare that our procedures for handling animals comply with the Current Laboratory Animal Laws Regulations, Policies \& Administration in China. ICR mice (merchandise purchased from Vital River Company in Beijing, China) were bred and maintained in our animal facility. All experiments were carried out according to the guidelines of the American Association for Laboratory Accreditation. For all pregnancy experiments, we considered the first day for the emergence of vaginal plug as day 0.5 of pregnancy.

\section{Mammary anlagen preparation and morphologic analysis}

ICR female mice in estrus were mated and the age of the embryo was determined by checking vaginal plugs. Noon of the day after copulation was counted as day 0.5 . The mouse embryos with different sexual identities were kept in phosphate buffered saline (PBS) solution on ice. For collection of embryonic mammary anlagen, mammary anlagen were isolated at $\mathrm{E}$ 14.5. Isolation and collection of mammary anlagen associated with surrounding tissues were performed using a sharp small knife to retain density and shape. Dissected single mammary anlagen were kept in phosphate buffered saline (PBS) solution on ice. Then the morphologic analysis was performed using light microscopy (TE2000; Nikon, Tokyo, Japan).

\section{Antibodies}

Antibodies against mouse antigens were purchased from BD Pharmingen unless otherwise specified, and included CD24-PE, CD49f-PE-cy5,
CD29-PE-cy5 (Biolegend, San Diego, CA), CD29-FITC (Serotec, Oxford, UK). Rat anti-CD49f and purified rat anti-CD29 antibodies were purchased from BD Pharmingen. We also used anti-keratin 14 (covance, Princeton, $\mathrm{NJ}$ ), anti-cytokeratin 18 (sigma, St. Louis, MO) and polyclonal rabbit anticytokeratin (Dako, Santa Clara, CA) antibodies.

\section{Immunostaining}

For tissue immunostaining, 3 or 4 mammary anlagen at a time were transferred by a fire-polished Pasteur pipette, and then mounted on slides. They were subsequently fixed in a chilled mixture (acetone: methanol = $1: 1)$ at $-20^{\circ} \mathrm{C}$ for $30 \mathrm{~min}$. Then the specimens were washed twice (15 min each time) by PBS and blocked for 30 min with goat serum in PBS. In addition, the cultured mammary anlagen were fixed in $4 \%$ neutral-buffered paraformaldehyde at $4{ }^{\circ} \mathrm{C}$ for $20 \mathrm{~min}$, and then blocked with the $5 \%$ bovine calf serum in PBS. Primary antibody staining was performed overnight at $4{ }^{\circ} \mathrm{C}$, whereas the secondary antibody staining was performed at room temperature for $1 \mathrm{~h}$. This experiment was performed as described previously (Han et al., 2006). To examine the immunostaining of mammary anlagen, a confocal laser scanning microscope (Zeiss, LSM 510 Meta, Germany) was applied to produce $0.6 \mu \mathrm{m}$ thick optical sections as described previously (Perrot-Applanat et al., 1997).

\section{Mammary anlagen culture and in vitro prolactin stimulation}

After mechanical dissociation with a sharp small knife and scissors, the tissues were placed in the culture medium (D/F12 medium with $10 \%$ FBS). To achieve the PRL stimulation, E14.5 mammary anlagen were cultured with $10 \mu \mathrm{g} / \mathrm{ml} \mathrm{PRL}$ for 24 hours, and compared to the control samples (cultured in normal D/F12 medium with no PRL stimulation).

\section{Cell labeling and flow cytometry analysis}

Mammary anlagen tissues were transferred in $0.1 \%$ trypsin solution at $37^{\circ} \mathrm{C}$ for $1.5 \mathrm{~min}$, and dissociated mechanically. In order to inhibit trypsin activity, we used corresponsive trypsin inhibitor (Sigma, St. Louis, MO). Then the cells from mammary anlagen were re-suspended in DPBS and sieved sequentially through a $40 \mu \mathrm{m}$ cell mesh to obtain single-cell suspensions. Blocking was performed in $1 \%$ BSA for $10 \mathrm{~min}$. Antibody incubations were performed at $4{ }^{\circ} \mathrm{C}$ for $15 \mathrm{~min}$. Cells were re-suspended in DPBS before analysis. Data analysis was performed on the single live cell gate using SUMMIT 4.0 software (http://www.Dakocytomation.com).

\section{Mammary fat pad (MPF) transplantation and analysis}

Twenty-one days old female Scid mice were used as recipients. Their inguinal mammary glands were surgically cleared of the endogenous epithelium as described previously (Smalley and Ashworth 2003). GFPICR mice were used as donors. For cell transplantation, the indicated numbers of GFP-ICR mice cells from sorting were injected into the cleared fat pads of female Scid mice by using a fire-polished Pasteur pipette. After 8 weeks, the glands were dissected and fixed in $4 \%$ paraformaldehydePBS at $4{ }^{\circ} \mathrm{C}$. Pieces of dissected outgrowths were embedded in paraffin blocks, processed by standard histological assays, and viewed using a fluorescence microscope.

\section{RNA isolation and microarray analysis}

Total RNA was isolated from indicated cell populations using an RNeasy micro kit (Qiagen, Inc., Valencia, CA), and was applied to create the target for microarray using a MessageAmpTMII aRNAAmplification Kit. The labeled cDNA from each cell population was fragmented and hybridized to Mouse Genome 430 2.0 Arrays (Affymetrix Genechip). Then the GeneChip arrays were washed and stained (streptavidin-phycoerythrin) on an Affymetrix Fluidics Station 450 followed by scanning with a GeneChip Scanner 3000. All reactions and microarray hybridization procedures were performed in CapitalBio Co. (Beijing, China) as described previously (Zhang et al., 2009a; Zhang et al., 2009b). Details can be found on the website of CapitalBio (http://www.capitalbio.com). The pathway analysis were depending on the database of KEGG BioCarta and GenMAPP. 


\section{Statistical analysis}

Each experiment was performed at least three times and the mean was used to calculate significance. Data were expressed as mean values \pm standard error mean (SEM). Data analyses were performed with the statistical software package Graph Pad Prism 5. Microsoft Office Excel and SigmaPlot were used to analyze the data from the array intensity and draw the histogram of the relative expression of different samples.

\section{Acknowledgements}

The authors would like to thank Hongkui Deng (College of Life Sciences, Peking University, Beijing, P. R. China) for providing the GFP transgenic $C D-1$ mice used in this study.

\section{Authors' contributions}

Jiazhe Song conceived and conducted all of the experiments. Manuscript drafts were written by Kai Xue. Jiazhe Song and Kai Xue participated in the study's design and coordination and assisted with manuscript drafts. Fangrong Ding and Song Li participated in the experiments for method validation. All authors have read and approved the final manuscript.

\section{Conflict of Interests}

The authors declare that they have no conflict of interest.

Funding

This work was supported by National Natural Science Foundation of China (No: 31101717).

\section{References}

ARENDT, L.M. and SCHULER, L.A. (2008). Prolactin drives estrogen receptor-alphadependent ductal expansion and synergizes with transforming growth factor-alpha to induce mammary tumors in males. Am J Pathol 172: 194-202.

BRIDGEWATER, R.E., STREULI, C.H. and CASWELL, P.T. (2017). Extracellular matrix promotes clathrin-dependent endocytosis of prolactin and STAT5 activation in differentiating mammary epithelial cells. Sci Rep 7: 4572.

DAMIANO, J.S. and WASSERMAN, E. (2013). Molecular pathways: blockade of the PRLR signaling pathway as a novel antihormonal approach for the treatment of breast and prostate cancer. Clin Cancer Res 19: 1644-1650.

DANIEL, C.W., SILBERSTEIN, G.B. and STRICKLAND, P. (1987). Direct action of 17 beta-estradiol on mouse mammary ducts analyzed by sustained release implants and steroid autoradiography. Cancer Res 47: 6052-6057.

FIORILLO, A.A., MEDLER, T.R., FEENEY, Y.B., WETZ, S.M., TOMMERDAHL, K.L. and CLEVENGER, C.V. (2013). The prolactin receptor transactivation domain is associated with steroid hormone receptor expression and malignant progression of breast cancer. Am J Pathol 182: 217-233.

GALLEGO, M.I., BEACHY, P.A., HENNIGHAUSEN, L. and ROBINSON, G.W. (2002), Differential requirements for shh in mammary tissue and hair follicle morphogenesis. Dev Biol 249: 131-139.

GUTZMAN, J.H., MILLER, K.K. and SCHULER, L.A. (2004). Endogenous human prolactin and not exogenous human prolactin induces estrogen receptor alpha and prolactin receptor expression and increases estrogen responsiveness in breast cancer cells. J Steroid Biochem Mol Biol 88: 69-77.

HAN, J., CAO, S., JIN, H., LIU, Y., WANG, M., SONG, J. and LI, N. (2006). Localization of putative stem cells and four cell populations with different differentiation degree in mouse mammary anlagen. Histochem Cell Biol 126: 35-43.

HARICHARAN, S. and LI, Y. (2014). STAT signaling in mammary gland differentiation, cell survival and tumorigenesis. Mol Cell Endocrinol 382: 560-569.

HORSEMAN, N.D. (1999). Prolactin and mammary gland development. J Mammary Gland Biol Neoplasia 4: 79-88.

HORSEMAN, N.D., ZHAO, W., MONTECINO-RODRIGUEZ, E., TANAKA, M., NAKASHIMA, K., ENGLE, S.J., SMITH, F., MARKOFF, E. and DORSHKIND, K. (1997). Defective mammopoiesis, but normal hematopoiesis, in mice with a targeted disruption of the prolactin gene. EMBO J 16: 6926-6935.
JIAZHE SONG, K., JISHE, FANGRONGDING, SONGLI, RULAN SHANGGUAN YUNPINGDAI, LIYINGDU, NINGLI. (2014). A mammary repopulating cell population characterized in mammary anlagen reveals essential mammary stroma for morphogenesis. Exp. Cell Res. 327: 123-134.

LEEHY, K.A., TRUONG, T.H., MAURO, L.J. and LANGE, C.A. (2018). Progesterone receptors (PR) mediate STAT actions: PR and prolactin receptor signaling crosstalk in breast cancer models. J Steroid Biochem Mol Biol 176: 88-93.

O'LEARY, K.A., SHEA, M.P., SALITURO, S., BLOHM, C.E. and SCHULER, L.A. (2017). Prolactin Alters the Mammary Epithelial Hierarchy, Increasing Progenitors and Facilitating Ovarian Steroid Action. Stem Cell Reports 9: 1167-1179.

OAKES, S.R., ROGERS, R.L., NAYLOR, M.J. and ORMANDY, C.J. (2008). Prolactin regulation of mammary gland development. J Mammary Gland Biol Neoplasia 13: $13-28$

PERROT-APPLANAT, M., GUALILLO, O., PEZET, A., VINCENT, V., EDERY, M. and KELLY, P.A. (1997). Dominant negative and cooperative effects of mutant forms of prolactin receptor. Mol Endocrinol 11: 1020-1032.

ROBINSON, G.W. (2007). Cooperation of signalling pathways in embryonic mammary gland development. Nat Rev Genet 8: 963-972.

ROBINSON, G.W., KARPF,A.B. and KRATOCHWIL, K. (1999). Regulation of mammary gland development by tissue interaction. J Mammary Gland Biol Neoplasia 4: 9-19.

ROBINSON, G.W., WAGNER, K.U. and HENNIGHAUSEN, L. (2001). Functional mammary gland development and oncogene-induced tumor formation are not affected by the absence of the retinoblastoma gene. Oncogene 20: 7115-7119.

ROSE-HELLEKANT, T.A., ARENDT, L.M., SCHROEDER, M.D., GILCHRIST, K., SANDGREN, E.P. and SCHULER, L.A. (2003). Prolactin induces ERalpha-positive and ERalpha-negative mammary cancer in transgenic mice. Oncogene22: 4664-4674.

SHACKLETON, M., VAILLANT, F., SIMPSON, K.J., STINGL, J., SMYTH, G.K., ASSELIN-LABAT, M.L., WU, L., LINDEMAN, G.J. and VISVADER, J.E. (2006). Generation of a functional mammary gland from a single stem cell. Nature 439: 84-88.

SILBERSTEIN, G.B., VAN HORN, K., SHYAMALA, G. and DANIEL, C.W. (1994) Essential role of endogenous estrogen in directly stimulating mammary growth demonstrated by implants containing pure antiestrogens. Endocrinol. 134: 84-90.

SMALLEY, M. and ASHWORTH, A. (2003). Stem cells and breast cancer: A field in transit. Nat Rev Cancer 3: 832-844.

SONG, J., SONG, J., XUE, K., HAN, H., DING, F., LI, S., DAI, Y. and LI, N. (2015). Rapid atraumatic sex identification of developmental day 14-16 mice. Biotech Histochem 90: 309-314.

SPIKE, B.T., ENGLE, D.D., LIN, J.C., CHEUNG, S.K., LA, J. and WAHL, G.M. (2012). A mammary stem cell population identified and characterized in late embryogenesis reveals similarities to human breast cancer. Cell Stem Cell 10: 183-197.

STINGL, J., EIREW, P., RICKETSON, I., SHACKLETON, M., VAILLANT, F., CHOI, D., LI, H.I. and EAVES, C.J. (2006). Purification and unique properties of mammary epithelial stem cells. Nature 439: 993-997.

TWOROGER, S.S., ELIASSEN, A.H., ZHANG, X., QIAN, J., SLUSS, P.M., ROSNER B.A. and HANKINSON, S.E. (2013). A 20 -year prospective study of plasma prolactin as a risk marker of breast cancer development. Cancer Res 73: 4810-4819.

VAN KEYMEULEN, A., ROCHA, A.S., OUSSET, M., BECK, B., BOUVENCOURT, G., ROCK, J., SHARMA, N., DEKONINCK, S. and BLANPAIN, C. (2011). Distinct stem cells contribute to mammary gland development and maintenance. Nature 479: 189-193

VELTMAAT, J.M., MAILLEUX, A.A., THIERY, J.P. and BELLUSCI, S. (2003). Mouse embryonic mammogenesis as a model for the molecular regulation of pattern formation. Differentiation 71: 1-17.

WALDEN, P.D., RUAN, W., FELDMAN, M. and KLEINBERG, D.L. (1998). Evidence that the mammary fat pad mediates the action of growth hormone in mammary gland development. Endocrinology 139: 659-662.

ZHANG, Q., ZHAO, X.H. and WANG, Z.J. (2009a). Cytotoxicity of flavones and flavonols to a human esophageal squamous cell carcinoma cell line (KYSE-510) by induction of G2/M arrest and apoptosis. Toxicol In Vitro 23: 797-807.

ZHANG, X.L., PENG, J., SUN, J.Z., LIU, J.J., GUO, C.S., WANG, Z.G., YU, Y., SHI, Y., QIN, P., LI, S.G., ZHANG, L.N. and HOU, M. (2009b). De novo induction of platelet-specific CD4(+)CD25(+) regulatory T cells from CD4(+)CD25(-) cells in patients with idiopathic thrombocytopenic purpura. Blood 113: 2568-2577. 


\section{Further Related Reading, published previously in the Int. J. Dev. Biol.}

Exosome signaling in mammary gland development and cancer

An Hendrix and Alistair N. Hume

Int. J. Dev. Biol. (2011) 55: 879-887

https://doi.org/10.1387/ijdb.113391ah

Insulin-like growth factor binding proteins and mammary gland development Angara Sureshbabu, Elizabeth Tonner and David J. Flint

Int. J. Dev. Biol. (2011) 55: 781-789

https://doi.org/10.1387/ijdb.113364as

Connexins: a junctional crossroad to breast cancer

Jamal A. El-Saghir, Elia T. El-Habre, Marwan E. El-Sabban and Rabih S. Talhouk

Int. J. Dev. Biol. (2011) 55: 773-780

https://doi.org/10.1387/ijdb.113372je

Remodeling mechanisms of the mammary gland during involution

Christine J. Watson and Peter A. Kreuzaler

Int. J. Dev. Biol. (2011) 55: 757-762

https://doi.org/10.1387/ijdb.113414cw

Non-steroidal anti-inflammatory drugs target the pro-tumorigenic extracellular matrix of the postpartum mammary gland

Jenean O'Brien, Kirk Hansen, Dalit Barkan, Jeffrey Green and Pepper Schedin

Int. J. Dev. Biol. (2011) 55: 745-755

https://doi.org/10.1387/ijdb.113379jo

Mammary gland stem cells: current status and future challenges

Agla J.R. Fridriksdottir, Ole W. Petersen and Lone Rønnov-Jessen

Int. J. Dev. Biol. (2011) 55: 719-729

https://doi.org/10.1387/ijdb.113373af

Ecosystems of invasion and metastasis in mammary morphogenesis and cancer Marc Mareel and Susana Constantino

Int. J. Dev. Biol. (2011) 55: 671-684

https://doi.org/10.1387/ijdb.113386mm

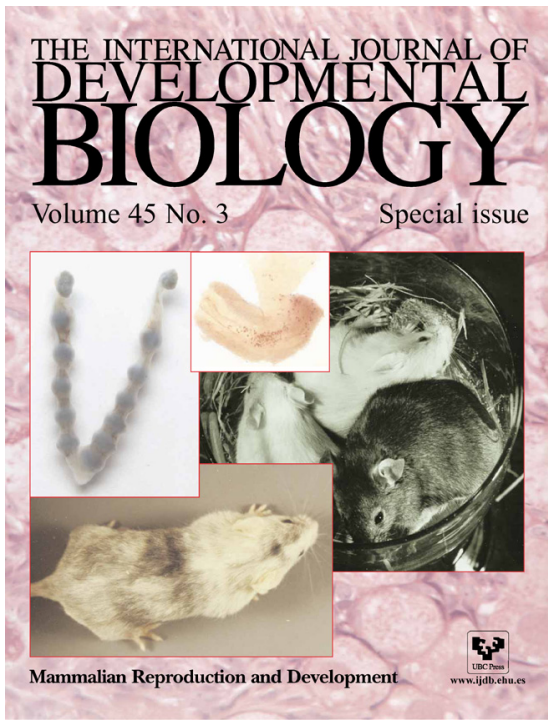

5 yr ISI Impact Factor $(2016)=2.421$
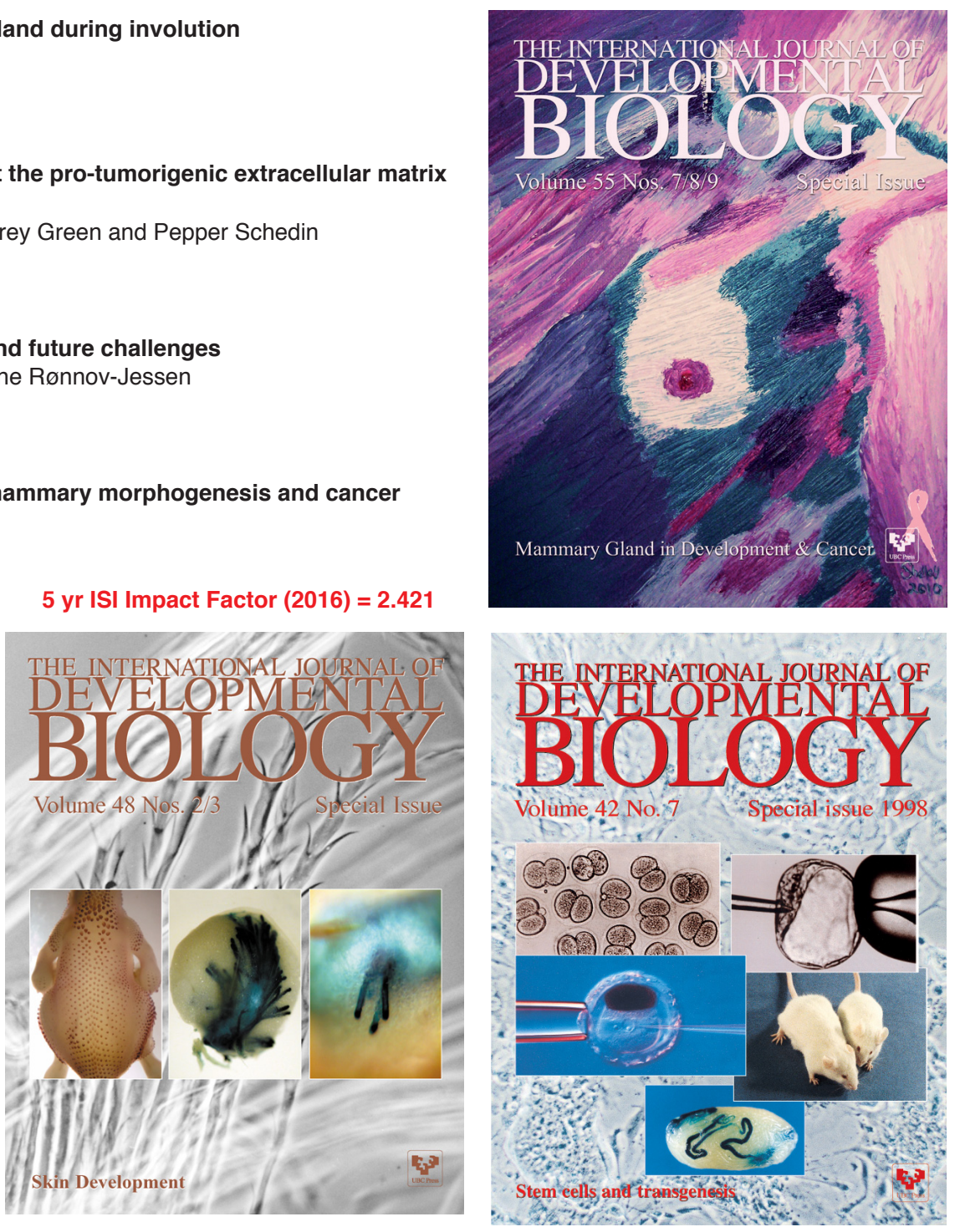